\title{
Hubungan Durasi Tidur dengan Kejadian Overweight dan Obesitas pada Tenaga Kependidikan di Lingkungan Kampus C Universitas Airlangga
}

\section{The Association between Sleep Duration with Overweight and Obesity Among Education Staff in Campus C of Universitas Airlangga}

\author{
Rachmania Eka Damayanti*1, Sri Sumarmi², Luki Mundiastuti ${ }^{3}$
}

\begin{abstract}
ABSTRAK
Latar Belakang: Masalah gizi yang banyak dialami orang dewasa salah satunya adalah obesitas. Obesitas dapat dipengaruhi oleh berbagai faktor antara lain pendeknya durasi tidur. Hal tersebut sering terjadi pada masyarakat pekerja kantor. Tujuan: Penelitian dilakukan untuk menganalisis hubungan antara durasi tidur dengan kejadian overweight dan obesitas pada tenaga kependidikan di Lingkungan Kampus C Universitas Airlangga.

Metode: Penelitian ini menggunakan desain case control. Kelompok kasus adalah tendik dengan IMT $\geq 23 \mathrm{~kg} / \mathrm{m}^{2} \mathrm{dan}$ kelompok kontrol adalah tendik dengan IMT $<23 \mathrm{~kg} / \mathrm{m}^{2}$ serta tidak sedang hamil sebagai kriteria inklusi. Besar sampel yaitu 80 orang dibagi menjadi kelompok kasus 40 orang dan kelompok kontrol 40 orang. Sampel diambil secara purposive. Variabel dependent adalah overweight dan obesitas sedangkan variabel independent adalah durasi tidur. Data diuji menggunakan regresi logistik.

Hasil: Pada kelompok kasus yang termasuk kategori Obese I sebesar $50 \%$ sedangkan pada kelompok kontrol yang termasuk kategori normal sebesar 92,5\%. Pada kelompok kasus yang memiliki durasi tidur pendek (< 7 jam) sebesar $95 \%$ sedangkan pada kelompok kontrol yang memiliki durasi tidur cukup (7-9 jam) sebesar 92,5\%. Adanya hubungan antara pendeknya durasi tidur dengan kejadian overweight dan obesitas ( $p<0,001 ; O R=7,70)$.

Kesimpulan: Pendeknya durasi tidur berhubungan dengan kejadian overweight dan obesitas pada tenaga kependidikan di lingkungan Kampus C UNAIR Surabaya. Durasi tidur yang kurang $(<7$ jam) memiliki risiko 7,702 kali lipat lebih tinggi untuk menjadi overweight dan obesitas dibandingkan mereka yang memiliki durasi tidur cukup (7-9 jam). Semakin pendek durasi tidur, maka risiko kejadian overweight dan obesitas semakin besar.
\end{abstract}

Kata kunci: durasi tidur, overweight dan obesitas

\section{ABSTRACT}

Background: One of the many nutritional problems experienced by adults is obesity. Obesity can be influenced by various factors including short sleep duration. This often happens to the office worker community.

Objectives: This research aim's to analyze relationship between sleep duration with overweight and obesity among education staff in Campus $C$ of Universitas Airlangga.

Method: This study was using case control design. The case group was education staff with $B M I \geq 23 \mathrm{~kg} / \mathrm{m}^{2}$ and the control group was education staff with $B M I<23 \mathrm{~kg} / \mathrm{m}^{2}$ and not pregnant as inclusion criteria. The sample was 80 people, divided into the case group was 40 people and the control group was 40 people. Samples were taken purposively. Dependent variables were overweight and obesity while the independent variable was sleep duration. Data was tested using logistic regression.

Results: In the case group, 50\% of participants were included in the Obese I, while in the control group, $92.5 \%$ of the participants were included in the normal category. In the case group that had short sleep duration ( $<7$ hours of $95 \%$ while in the control group had enough sleep duration (7-9 hours) of 92.5\%. There was significant correlation between short sleep duration with overweight and obesity ( $p<0.001 ; O R=7.70)$.

Conclusion: The short sleep duration is related to overweight and obesity among educational staff in the Campus $C$ of Universitas Airlangga. Sleep duration ( $<7$ hours) has a risk of 7.702 times higher for being overweight and obesity than those who have enough sleep (7-9 hours). The shorter of sleep duration, the greater risk occurrence of overweight and obesity.

Keywords: sleep duration, overweight and obesity

*Koresponden:

ekarchmnia12@gmail.com

1,2Departemen Gizi Kesehatan, Fakultas Kesehatan Masyarakat, Universitas Airlangga, Kampus C Mulyorejo, 60115, Surabaya, Jawa Timur

${ }^{3}$ Akademi Gizi Surabaya, Jl. Bendul Merisi No.126, Wonocolo, 60239, Surabaya, Jawa Timur, Indonesia 


\section{PENDAHULUAN}

Kejadian overweight dan obesitas telah menjadi masalah kesehatan yang dipengaruhi oleh berbagai faktor antara lain usia dan jenis kelamin. ${ }^{1}$ Overweight dan obesitas merupakan kondisi kelebihan berat badan akibat penyimpanan lemak yang berlebih. ${ }^{2}$ Overweight dan obesitas bisa diketahui dengan mengukur Indeks Massa Tubuh (IMT). ${ }^{3}$ Prevalensi obesitas dan overweight pada orang dewasa ( $>18$ tahun) di dunia cenderung meningkat yakni prevalensi obesitas (IMT $\geq 30 \mathrm{~kg} / \mathrm{m}^{2}$ ) sebesar 39\%, sedangkan prevalensi overweight (IMT $\geq 25$ $\mathrm{kg} / \mathrm{m}^{2}$ ) sebesar $11 \%$ (laki-laki) dan $15 \%$ (perempuan). ${ }^{4}$ Berdasarkan hasil Riskesdas (2018), menyatakan bahwa prevalensi obesitas pada orang dewasa semakin meningkat sejak tiga periode Riskesdas yakni 10,5\% (Riskesdas 2007), 14,8\% (Riskesdas 2013) dan 21,8\% (Riskesdas 2018). ${ }^{5,6}$ Sementara itu, prevalensi obesitas pada orang dewasa di Jawa Timur sekitar $22 \%$ di atas rata-rata presentase nasional sebesar $21,8 \% .{ }^{7}$

Permasalahan gizi pada orang dewasa cenderung mengarah pada obesitas. ${ }^{8}$ Faktor-faktor yang mempengaruhi obesitas antara lain umur, jenis kelamin, genetik, aktivitas fisik, pola makan, gaya hidup, dan salah satunya adalah durasi tidur. ${ }^{9}$ Penurunan rata-rata durasi tidur diikuti dengan meningkatnya prevalensi obesitas pada orang dewasa. ${ }^{10}$ Berkurangnya waktu tidur menyebabkan ketidakseimbangan hormon, yakni meningkatnya hormon ghrelin dan menurunnya kadar hormon leptin yang memicu peningkatan nafsu makan di malam hari. ${ }^{11}$ Menurut Depkes, durasi tidur orang dewasa usia 18 tahun ke atas normalnya $<7$ jam per hari. ${ }^{12}$

Hasil penelitian meta analisis oleh Safitri dan Sudiarti menunjukkan bahwa prevalensi obesitas pada orang dewasa dengan durasi tidur $<7$ jam per hari lebih besar $42 \%$ daripada prevalensi orang dewasa dengan durasi tidur $>7$ jam per hari. penelitian menunjukkan seseorang yang memiliki durasi tidur $\leq 5$ jam per hari berisiko lebih tinggi terhadap obesitas. Selain itu, pekerja kantor adalah salah satu jenis pekerjaan yang rentan terhadap masalah gizi lebih. ${ }^{13,14,15} \mathrm{Hal}$ tersebut diperkuat pula dengan hasil analisis Riskesdas yang menunjukkan bahwa pegawai/pegawai negeri sipil berada di tingkat pertama berisiko obesitas sebesar $24,4 \%$. Dapat dikatakan bahwa tenaga kependidikan memiliki karakteristik yang hampir sama, sehingga diperkirakan jenis pekerjaan ini memiliki kerentanan terhadap kejadian obesitas.

Berdasarkan uraian tersebut, diperlukan adanya penelitian untuk menganalisis hubungan durasi tidur dengan kejadian overweight dan obesitas pada tenaga kependidikan di Lingkungan Kampus C Universitas Airlangga.

\section{METODE}

Penelitian ini menggunakan desain case control. Populasi penelitian ini adalah tenaga kependidikan di lingkungan Kampus C Universitas Airlangga diantaranya Fakultas Kesehatan Masyarakat (FKM), Fakultas Sains dan Teknologi (FST), Fakultas Keperawatan (FKP),
Fakultas Perikanan dan Kelautan (FPK) dan Fakultas Kedokteran Hewan (FKH). Sampel pada penelitian ini masing-masing adalah 40 orang yang didapatkan dengan rumus Lemeshow sehingga diperoleh jumlah sampel yang dibutuhkan sebanyak 80 orang dan terbagi atas dua kelompok yaitu kelompok kasus (IMT $\geq 23 \mathrm{~kg} / \mathrm{m}^{2}$ ) dan kelompok kontrol (IMT $<23 \mathrm{~kg} / \mathrm{m}^{2}$ ) dengan kriteria inklusi tidak sedang hamil. Teknik yang digunakan adalah purposive sampling. Pemilihan sampel dalam teknik purposive sampling menggunakan kriteria yang ditentukan peneliti agar bisa mendapatkan sampel yang sesuai dengan kegiatan penelitian. Penelitian ini dilakukan selama Agustus sampai September 2018.

Pada penelitian ini variabel dependen adalah overweight dan obesitas sedangkan variabel independen adalah durasi tidur. Indeks Massa Tubuh (IMT) responden dihitung berdasarkan pengukuran tinggi badan dan berat badan. Pengukuran tinggi badan diukur menggunakan microtoise merk GEA dengan ketelitian $0,1 \mathrm{~cm}$ dan pengukuran berat badan diukur menggunakan timbangan digital merk Kris dengan ketelitian 0,1 kg. Selanjutnya, data IMT dikategorikan menjadi 2 kelompok yaitu kelompok kasus (IMT $\geq 23$ $\mathrm{kg} / \mathrm{m}^{2}$ ) dan kelompok kontrol (IMT $<23 \mathrm{~kg} / \mathrm{m}^{2}$ ). Instrumen yang digunakan adalah kuesioner identitas dan kuesioner durasi tidur. Kuesioner identitas untuk mencatat karakteristik antara lain jenis kelamin, usia, tinggi badan, berat badan, dan tingkat pendidikan terakhir. Kuesioner durasi tidur berisikan 5 pertanyaan terbuka yang meliputi rata-rata durasi tidur malam per hari, rata-rata waktu bangun di pagi hari, dan rata-rata waktu mulai tidur di malam hari. yang harus dijawab oleh responden. Uji regresi logistik digunakan untuk menguji hubungan antar variabel dan mengetahui faktor risiko kejadian overweight dan obesitas.

Penelitian ini telah mendapat persetujuan layak etik dari Komisi Etik Fakultas Kesehatan Masyarakat Universitas Airlangga dengan nomor 451-KEPK tanggal 25 Juli 2018. Setiap responden telah menyetujui ikut serta dalam penelitian ini menandatangani informed consent.

\section{HASIL DAN PEMBAHASAN}

Distribusi karakteristik responden berdasarkan usia, jenis kelamin dan tingkat pendidikan disajikan Tabel 1. Distribusi usia kedua kelompok didominasi oleh kelompok usia 26 - 35 tahun. Distribusi jenis kelamin kedua kelompok didominasi oleh laki - laki. Begitu pula, distribusi tingkat pendidikan kedua kelompok sebagian besar merupakan tamat $\mathrm{S} 1$.

Hasil penelitian sebelumnya menyatakan bahwa metabolisme semakin menurun seiring bertambahnya usia dan diikuti perubahan secara biologis yakni fungsi otot yang menurun dan kadar lemak yang meningkat pada tubuh. Hal tersebut sejalan dengan penelitian lain yang menunjukkan bahwa semakin bertambahnya usia maka semakin berisiko mengalami obesitas karena terjadi peningkatan akumulasi lemak di dalam tubuh yang didukung oleh perubahan pola makan yang tidak seimbang yaitu tinggi karbohidrat, tinggi lemak dan rendah serat. Dengan kata lain kejadian kegemukan cenderung meningkat pada usia dewasa. ${ }^{16}$ 
Pada penelitian ini sebagian besar responden adalah laki-laki. Komposisi tubuh laki-laki berbeda dengan perempuan meskipun dengan usia, tinggi badan, dan berat badan yang sama. Laki-laki cenderung memiliki banyak otot daripada perempuan. ${ }^{17}$ Berdasarkan penelitian ini sebagian besar tingkat pendidikan responden adalah tamat perguruan tinggi (S1). Tingkat pendidikan mempengaruhi perilaku konsumsi pangan melalui cara pemilihan bahan makanan. ${ }^{18}$ Begitu pula dalam kaitannya dengan risiko obesitas, semakin tinggi pendidikan seseorang maka dianggap semakin baik tingkat pengetahuan gizinya sehingga kemungkinan dalam mengonsumsi pangan tidak seimbang menurun dan mengurangi resiko terhadap kegemukan. ${ }^{19}$ Hasil penelitian sebelumnya menyatakan apabila peluang kejadian obesitas hampir 3 kali lipat lebih tinggi pada responden dengan pendidikan tinggi dibandingkan pada responden dengan pendidikan rendah. Sebagian besar responden yang berpendidikan tinggi mengalami obesitas sebab umumnya pekerjaan mereka semakin baik sehingga tingkat pendapatannya semakin tinggi. ${ }^{20}$ Peningkatan pendapatan akan berpengaruh pada gaya hidup seperti perubahan pola makan. ${ }^{21}$

Tabel 1. Distribusi Karakteristik pada Tenaga Kependidikan di Lingkungan Kampus C UNAIR Surabaya Tahun 2018

\begin{tabular}{lcccc}
\hline \multirow{2}{*}{ Kategori } & \multicolumn{2}{c}{ Kasus } & \multicolumn{2}{c}{ Kontrol } \\
\cline { 2 - 5 } & $\mathbf{n}$ & $\mathbf{\%}$ & $\mathbf{n}$ & $\%$ \\
\hline Usia & & & & \\
26-35 tahun & 15 & 37,5 & 11 & 27,5 \\
36-45 tahun & 14 & 35 & 11 & 27,5 \\
46-55 tahun & 8 & 20 & 17 & 42,5 \\
56-65 tahun & 3 & 7,5 & 1 & 2,5 \\
\hline Jenis Kelamin & & & & \\
Laki-laki & 29 & 72,5 & 29 & 72,5 \\
Perempuan & 11 & 27,5 & 11 & 27,5 \\
\hline Tingkat & & & & \\
Pendidikan & & & & \\
Tamat SMA & 17 & 42,5 & 14 & 35 \\
Tamat D3 & 4 & 10 & 4 & 10 \\
Tamat S1 & 19 & 47,5 & 22 & 55 \\
\hline
\end{tabular}

Tabel 2 menunjukkan bahwa pada kelompok kasus rata-rata IMT responden adalah $27,46 \mathrm{~kg} / \mathrm{m}^{2} \pm$ 3,40 dengan IMT minimum $23,13 \mathrm{~kg} / \mathrm{m}^{2}$ dan IMT maksimum $36,92 \mathrm{~kg} / \mathrm{m}^{2}$. Sementara itu, pada kelompok kontrol rata-rata IMT responden adalah $21,20 \mathrm{~kg} / \mathrm{m}^{2} \pm$ 1,66 dengan IMT minimum $17,07 \mathrm{~kg} / \mathrm{m}^{2}$ dan IMT maksimum 22,92 kg/m². Tabel 3 menunjukkan bahwa rata-rata durasi tidur kelompok kasus adalah 5,5 jam \pm 0,7415 dengan durasi tidur minimum 4 jam dan durasi tidur maksimum 6,5 jam. Rerata durasi tidur kelompok kontrol adalah 7 jam $\pm 0,3359$ dengan durasi tidur minimum 6,5 jam dan durasi tidur maksimum 8 jam.

Tabel 4 menunjukkan bahwa pada kelompok kasus dengan durasi tidur kurang dari 7 jam sebesar $95 \%$ sedangkan pada kelompok kontrol responden dengan durasi tidur cukup 7-9 jam sebesar 92,5\%.
Tabel 2. Distribusi Indeks Massa Tubuh pada Tenaga Kependidikan di Lingkungan Kampus C UNAIR Surabaya Tahun 2018

\begin{tabular}{lcc}
\hline & Kasus & Kontrol \\
\hline$\overline{\boldsymbol{x}} \pm$ SD & $27,46 \pm 3,40$ & $21,20 \pm 1,66$ \\
Min & 23,13 & 17,07 \\
Maks & 36,92 & 22,92 \\
\hline
\end{tabular}

Tabel 3. Distribusi Durasi Tidur pada Tenaga Kependidikan di Lingkungan Kampus C UNAIR Surabaya Tahun 2018

\begin{tabular}{|c|c|c|}
\hline & Kasus & Kontrol \\
\hline $\boldsymbol{x} \pm \mathrm{SD}$ & $5,588 \pm 0,7415$ & $7,050 \pm 0,3359$ \\
\hline Min & 4 & 6,5 \\
\hline Maks & 6,5 & 8 \\
\hline
\end{tabular}

Hasil penelitian sebelumnya menunjukkan bahwa prevalensi kelompok orang dewasa obesitas yang durasi tidurnya $<7$ jam per hari sebesar $42 \%$ lebih besar daripada kelompok orang dewasa yang tidak obesitas. ${ }^{22}$ Hasil uji regresi logistik didapatkan sebesar $<0,001$ $(<0,05)$ yang menunjukkan bahwa ada hubungan yang signifikan antara durasi tidur kurang dengan kejadian overweight dan obesitas pada tenaga kependidikan di lingkungan Kampus C Universitas Airlangga. Di samping itu, dapat diketahui bahwa responden yang memiliki durasi tidur kurang dari 7 jam memiliki risiko 7,702 kali lipat lebih tinggi untuk menjadi overweight dan obesitas dibandingkan responden yang memiliki durasi tidur cukup (7-9 jam).

Artinya, responden dengan durasi tidur kurang cenderung mengalami overweight atau obesitas. Terdapat penelitian sebelumnya yang sejalan dengan penelitian ini, menunjukkan bahwa ada hubungan antara durasi tidur dengan kejadian obesitas pada polisi. Responden yang memiliki durasi tidur $<7$ jam beresiko terkena obesitas sebesar 3,8 kali dibandingkan dengan responden dengan durasi tidur cukup ( $\geq 7$ jam). ${ }^{23}$ Hasil meta analisis menyebutkan bahwa selera makan yang berlebih dapat dipengaruhi oleh pendeknya durasi tidur. ${ }^{24}$ Durasi tidur normal pada usia dewasa yaitu 7 hingga 9 jam per hari. ${ }^{25}$

Durasi tidur memiliki peran terhadap pengaturan metabolisme hormon leptin dan ghrelin, sehingga durasi tidur yang singkat di malam hari berpengaruh pada ketidakseimbangan hormon. ${ }^{26}$ Durasi tidur yang kurang dapat meningkatkan nafsu makan karena terjadi peningkatan hormon ghrelin dimana hormon ini berfungsi untuk meningkatkan nafsu makan seseorang dan menurunkan hormon leptin dimana hormon ini yang berfungsi untuk mengendalikan nafsu makan seseorang. ${ }^{27,28}$ Terdapat pula Neuropeptide $Y$ yang berfungsi merangsang nafsu makan. ${ }^{29}$ Leptin bekerja dengan menghambat pengeluaran Neuropeptide $Y$ di hipotalamus namun apabila hormon leptin menurun maka leptin tidak bisa merangsang hipotalamus untuk menurunkan produksi Neuropeptide $Y$ akibatnya terjadi peningkatan nafsu makan. ${ }^{30}$ 
Tabel 4. Tabulasi Silang Durasi Tidur dengan Kejadian Overweight dan Obesitas pada Tenaga Kependidikan di Lingkungan Kampus C UNAIR Surabaya Tahun 2018

\begin{tabular}{|c|c|c|c|c|c|c|c|c|}
\hline \multirow{2}{*}{ Durasi Tidur } & \multicolumn{2}{|c|}{ Kasus } & \multicolumn{2}{|c|}{ Kontrol } & \multirow{2}{*}{$p$-value } & \multirow{2}{*}{ OR } & \multicolumn{2}{|c|}{$95 \% \mathrm{Cl}$} \\
\hline & $\mathrm{n}$ & $\%$ & $\mathbf{n}$ & $\%$ & & & Lower & Upper \\
\hline Kurang & 38 & 95 & 3 & 7,5 & & & & \\
\hline Cukup & 2 & 5 & 37 & 92,5 & $<0,001$ & 7,702 & 3,077 & 19,278 \\
\hline Total & 40 & 100 & 40 & 100 & & & & \\
\hline
\end{tabular}

Ketidakseimbangan hormon antara hormon leptin, ghrelin dan NPY yang berpengaruh pada peningkatan nafsu makan di malam hari, meningkatkan kesempatan seseorang untuk mengonsumsi makanan atau cemilan di malam hari, sedangkan makanan atau cemilan yang dikonsumsi seseorang di malam hari cenderung makanan seperti junk food. ${ }^{31} \mathrm{Hal}$ ini dapat mempengaruhi terhadap terjadinya overweight atau obesitas pada seseorang.

\section{KESIMPULAN}

Berdasarkan penelitian ini, ketika durasi tidur semakin pendek maka risiko untuk terjadinya overweight dan obesitas semakin besar. Oleh karena itu disarankan agar menerapkan durasi tidur cukup 7 hingga 9 jam per hari untuk menjaga keseimbangan hormon yang berperan dalam terjadinya overweight dan obesitas.

\section{ACKNOWLEDGEMENT}

Peneliti mengucapkan terima kasih kepada seluruh responden. Penghargaan diberikan peneliti kepada seluruh staff pengajar program Studi S1 Gizi Fakultas Kesehatan Masyarakat Universitas Airlangga atas bimbingan dan dukungan yang telah diberikan.

\section{REFERENSI}

1. Prio, P. Durasi Tidur Singkat dan Obesitas. J Mojority 4, 5-9 (2015).

2. World Health Organization. Appropriate BodyMass Index for Asian Populations and Its Implications For Policy and Intervention Strategies. The Lancet 363, 157-163 (2004).

3. Depkes. Pedoman Praktis Memantau Status Gizi Orang Dewasa. (Depkes, 2011).

4. World Health Organization. Prevalence of Overweight and Obesity Among Adults. (WHO, 2016).

5. Kementrian Kesehatan RI. Hasil Utama Riskesdas 2018. (Kemenkes, 2018).

6. Badan Penelitian dan Pengembangan Kesehatan. Riset Kesehatan Dasar (RISKESDAS) 2013. Lap. Nas. 2013 1-384 (2013).

7. Dinkes Provinsi Jatim. Profil Kesehatan Provinsi Jawa Timur Tahun 2016. (Dinkes Provinsi Jatim, 2016).

8. Novitasary, M. D., Mayulu, N. \& Kawengian, S. E. . Hubungan Antara Aktivitas Fisik dengan Obesitas pada Wanita Usia Subur Peserta JAMKESMAS di Puskesmas Wawonasa Kecamatan Singkil Manado. J. e-Biomedik 1, 1040-1046 (2013).
Kualitas Tidur Hubungannya dengan Obesitas pada Anak Sekolah Dasar di Kota Yogyakarta dan Kabupaten Bantul. J. Gizi dan Diet. Indones. Indonesian J. Nutr. Diet. 1, 93-101 (2016).

10. Cassidy, S., Chau, J.Y., Catt, M., Bauman, A., \& Trenell, M. Low Physical Activity, High Television Viewing and Poor Sleep Duration Cluster in Overweight and Obese Adults. Int. J. Behav. Nutr. Phys. Act. 14, 57 (2017).

11. Grander, S., \& Krike., L. Short Sleep Duration is Associated with Reduced Leptin, Elevated Ghrelin, and Increased Body Mass Index. Plos Med. 1, 62 (2014).

12. Kementrian Kesehatan RI. Kebutuhan Tidur Sesuai Usia. (Kemenkes, 2011).

13. Indriani, S. D., Chandra, F. \& Masdar, H. Hubungan antara Pengetahuan dan Sikap dengan Kejadian Obesitas pada Pegawai Sekretariat Daerah Provinsi Riau. J. Online Mhs. 1, 1-6 (2014).

14. Sikalak, W., Widajanti, L. \& Aruben, R. FaktorFaktor yang Berhubungan dengan Kejadian Obesitas pada Karyawati Perusahaan di Bidang Telekomunikasi Jakarta Tahun 2017. J. Kesehat. Masy. 5, 193-201 (2017).

15. Dewi, A. C. N. \& Mahmudiono, T. Hubungan Pola Makan, Aktivitas Fisik, Sikap, dan Pengetahuan Tentang Obesitas dengan Status Gizi Pegawai Negeri Sipil di Kantor Dinas Kesehatan Provinsi Jawa Timur. J. Media Gizi Indones. 9, 42-48 (2013).

16. Ujiani, S., Analis, J. \& Poltekkes, K. Hubungan Antara Usia dan Jenis Kelamin dengan Kadar Kolesterol Penderita Obesitas RSUD Abdul Moeloek Provinsi Lampung. J. Kesehat. 4, 43-48 (2014).

17. Almatsier. Prinsip Dasar Ilmu Gizi. (Gramedia Pustaka Utama, 2009).

18. Puspitasari, N. Faktor Kejadian Obesitas Sentral pada Usia Dewasa. Higea J. Public Heal. Res. Dev. 2, 249-259 (2018).

19. Eslita, L. R. Hubungan Antara Tingkat Pendidikan dan Pekerjaan dengan Obesitas pada Wanita Dewasa, Kecamatan Ampel, Kabupaten Boyolali. (UMS, 2018).

20. Christina, D., Ayu, R. \& Sartika, D. Obesitas pada Pekerja Minyak dan Gas. Natl. Public Heal. J. 6, 104-110 (2011).

21. Parengkuan, R.R., Mayulu, N., Ponidjan, T. Hubungan Pendapatan Keluarga dengan Kejadian Obesitas pada Anak Sekolah Dasar di Kota Manado. J. Keperawatan 1, 1-7 (2013).

22. Safitri, D., \& Sudiarti, T. Perbedaan Durasi Tidur Malam pada Orang Dewasa Obesitas dan NonObesitas: Meta Analisis Studi Cross Sectional 
2005-2012. Penelit. Gizi dan Makanan 38, 121132 (2015).

23. Kurniawati, Y., Fakhriadi, R. \& Yulidasari, F. Hubungan Antara Pola Makan, Asupan Energi, Aktivitas Fisik dan Durasi Tidur dengan Kejadian Obesitas pada Polisi. Kesehat. Masy. Indones. 3, 112-117 (2016).

24. Chapman, Daniel C., Benedict C., Brooks S.J., \& S. H. B. Lifestyle Determinants of The Drive to Eat: A Meta-Analysis. Am J Clin Nutr 96, 492-7 (2012).

25. Nelson. Ilmu Kesehatan Anak Esensial. (Saunders Elvesier, 2014).

26. Ramadhaniah, Julia, M. \& Huriyati, E. Jurnal Gizi Klinik Indonesia Durasi Tidur, Asupan Energi, dan Aktivitas Fisik dengan Kejadian Obesitas pada Tenaga Kesehatan Puskesmas. J. Gizi Klin. Indones. 11, 85-96 (2014).
27. Nuraliyah, Syam, A., H. Aktivitas Fisik dan Durasi Tidur pada Penderita Overweight dan Obesitas Mahasiswa Universitas Hasanuddin. e-Journal 11, 1-11 (2013).

28. Harikedua, V. T., \& Tando, N. M. Aktivitas Fisik dan Pola Makan dengan Obesitas Sentral pada Tokoh Agama di Kota Manado. GIZIDO 4, 289298 (2012).

29. Meutia, N. Peran Neuropeptida Y dalam Meningkatkan Nafsu Makan. e-USU Repository 1-14 (2005).

30. Cahyaningrum, A. Leptin Sebagai Indikator Obesitas. J. Kesehat. Prima 9, 1364-1371 (2011).

31. Angels, M. R. et al. Gambaran durasi tidur pada remaja dengan kelebihan berat badan. J. eBiomedik 1, 849-853 (2013). 